\title{
Avaliação da Esteroidogênese das Supra-Renais em Mulheres Normais por Meio dos Testes de ACTH Simples de Depósito
}

Tese de Mestrado, apresentada à Universidade Federal de São Paulo Escola Paulista de Medicina - em 13/12/97

Autor: Vicente Lau

Orientador: Prof. Dr. Edmund Chada Baracat

A hiperplasia congênita das supra-renais decorre de defeito em qualquer uma das cinco etapas da síntese de cortisol. Todas possuem transmissão de caracter autossômico recessivo. Tanto as formas clássicas como as tardias são descritas em todos os tipos de deficiência enzimática.

A análise dos níveis basais dos esteróides e o estudo do seu perfil pós-estímulo com ACTH simples constituem os principais meios diagnósticos destas moléstias. O ACTH simples possui meia-vida curta, no entanto, a sua forma de depósito apresenta meia-vida longa, podendo estimular de maneira mais intensa as supra-renais.

Assim, realizamos estudo comparativo de estímulo das supra-renais com essas duas preparações de ACTH, em nove mulheres normais, na fase folicular precoce após tratamento prévio de 1,0 mg dexametasona na noite anterior. O ACTH simples foi administrado na dose de 0,25 mg, em infusão endovenosa em bolo, coletando-se sangue nos tempos de 0,30 e 60 minutos. No teste com ACTH depot empregou-se $1,0 \mathrm{mg}$, por via intramuscular; as amostras de sangue foram colhidas nos períodos de 0,12 e 24 horas. Foram utilizados os testes de Friedman e Wilcoxon para a análise estatística.

O estímulo esteroidogênico após o teste intramuscular com ACTH depot foi semelhante (17 $\alpha$-hidroxipregnenolona, DHEA e SDHEA) ou superior (17 $\alpha$-hidroxiprogesterona, 11-desoxicortisol, cortisol, 496 androstenediona, testosterona) ao teste endovenoso com ACTH simples, podendo constituir, pois, em importante subsídio para o diagnóstico das diversas formas de hiperplasia congênita das supra-renais.

\section{A Dopplervelocimetria com Mapeamento em Cores dos Ramos Intramiometriais da Artéria Uterina de Mulheres na Pós-Menopausa, com e sem Carcinoma de Endométrio}

Tese de Mestrado, apresentada à Universidade Federal de São Paulo -

Escola Paulista de Medicina - em 11/12/97

Autor: Maria Paula Ribas Caramuru

Orientador: Prof. Dr. Wagner José Gonçalves

Avaliaram-se 45 pacientes na pósmenopausa, sendo $31 \mathrm{com}$ queixa de sangramento genital da pós-menopausa assistidas no Setor de Oncocirurgia da Disciplina de Ginecologia da Escola Paulista de Medicina da Universidade Federal de São Paulo.

As mulheres submeteram-se à ultrasonografia transvaginal para medir a espessura do eco endometrial, seguida pela dopplervelocimetria de ramos intramiometriais da artéria uterina, obtendo-se os índices da resistência (IR) e de pulsatilidade (IP). A seguir procedeu-se à biópsia de endométrio em quatro quadrantes com cureta de Novak modificada para o estudo histopatológico endometrial.

O volume uterino e a espessura do eco endometrial foram significantemente menores nas pacientes com endométrio atrófico, quando comparados com aquelas com endométrio ativo e com neoplasia maligna.

Para detecção de neoplasia maligna do endométrio, quando se empregou o limite de espessura do eco endometrial de oito $\mathrm{mm}$, a sensibilidade do ultra-som foi de $100 \%$, a especialidade de $55,2 \%$, o valor preditivo positivo de $55,2 \%$ e, o negativo, de $100 \%$. 
A sensibilidade na detecção desta neoplasia foi de $81,2 \%$, a especificidade de $93,1 \%$, o valor preditivo positivo de $86,7 \%$ e o valor preditivo negativo de $90,0 \%$ quando o valor limite adotado para o IR dos vasos intramiometriais foi de 0,60 .

Estabelecendo-se o limite de 1,0 para o IP, obtivemos sensibilidade de $87,5 \%$, especificidade de $89,6 \%$, valor preditivo positivo de $82,3 \%$ e valor preditivo negativo de $92,9 \%$.
Nossos achados não nos permitem substituir a total investigação histopatológica da cavidade uterina por esses métodos. Entretanto, a utilização da ultra-sonografia transvaginal associada ao doppler colorido deverá diminuir o número de curetagens desnecessárias, especialmente quando a causa do sangramento genital da pós-menopausa for o endométrio atrófico.

\section{Avaliação Longitudinal de Aspectos Imunológicos e Virológicos Durante a Gravidez e Puerpério em Mulheres Portadoras do Vírus da Imunodeficiência Humana Tipo 1 (HIV-1)}

Tese de Doutorado, apresentada ao Departamento de Ginecologia e Obstetrícia da Faculdade de Medicina de Ribeirão Preto-USP - em 09/05/97

Autor: Silvana Maria Quintana

Orientador: Prof. Dr. Geraldo Duarte

As controvérsias a respeito das influências da gravidez e da infecção pelo vírus da imunodeficiência humana tipo 1 (HIV-1) sobre as contagens dos principais elementos da defesa celular e a necessidade de comprovação do padrão de mutações virais presentes nesta população, foram os principais fundamentos do presente estudo.

Para efetivar estes objetivos foi realizado um estudo longitudinal avaliando 22 mulheres durante a gestação e puerpério, das quais 11 eram portadoras do HIV-1 (grupo A) e 11 soronegativas para esta infecção (grupo B).

Cada paciente foi submetida a cinco coletas sangüíneas, uma a cada trimestre e duas no puerpério (40 dias e 6 meses após o parto). Os parâmetros da função imunológica avaliados foram as contagens de linfócitos totais, linfócitos T e suas subpopulações (TCD4 e TCD8), a relação CD4/CD8, as contagens de linfócitos B e NK (CD16+/CD3-, CD56+/CD3- e CD56+/CD16+). Concomitantemente foram selecionadas 20 mulheres não-grávidas, caracterizadas como grupo controle (dez mulheres portadoras do HIV-1 e dez mulheres soronegativas). Em 20 pacientes foram seqüenciados fragmentos genômicos de amostras do HIV-1, utilizando métodos de biologia molecular.
Observou-se que as contagens de linfócitos totais, linfócitos T, linfócitos TCD4 (\% e absoluto) e a relação CD4/CD8 foram significativamente mais baixas nas gestantes portadoras do HIV-1. As contagens de linfócitos $\mathrm{B}$ não foram diferentes entre as gestantes dos grupos A e B e os linfócitos TCD8 foram significativamente mais elevados no grupo A (gestantes soropositivas).

Em relação aos linfócitos NK, observou-se que os CD56+/CD16+ foram significativamente mais baixos durante a gravidez e período pós-parto de mulheres portadoras do HIV-1 quando comparadas com o grupo B.

O seqüenciamento e fragmentos do HIV-1 mostrou um elevado percentual de mutações na região da alça V3 $(75 \%)$ o tetrâmero GWGR foi o mais freqüente $(35 \%)$ nos grupos estudados (A e C) e uma nova variante (RWGR) foi observada.

Com base nos resultados deste trabalho, não foi possivel evidenciar influência da gestação sobre a evolução das contagens de linfócitos totais, relação CD4/CD8 e NK (CD56+/CD16+). Verificouse que as contagens de TCD4 não foram influenciadas pela gestação, mas apresentaram declínio no puerpério remoto, tanto no grupo A quanto no grupo B. 